\title{
Two-year results of a feasibility study on antireflux transoral incisionless fundoplication using EsophyX
}

\author{
Guy-Bernard Cadière $\cdot$ Nathalie Van Sante $\cdot$ \\ Jaime E. Graves · Anna K. Gawlicka • \\ Amin Rajan
}

Received: 12 June 2008/Accepted: 12 January 2009/Published online: 14 March 2009

(c) The Author(s) 2009. This article is published with open access at Springerlink.com

\begin{abstract}
Background A feasibility study $(n=19)$ evaluated the safety and initial efficacy of transoral incisionless fundoplication (TIF) for the treatment of gastroesophageal disease (GERD). The results at 1 year $(n=17)$ indicated that TIF was safe and had a significant effect on reducing GERD symptoms, proton pump inhibitor (PPI) usage, acid exposure, and small hiatal hernia. This study was designed to evaluate the long-term safety and durability of TIF.

Methods Fourteen patients (50\% female; median age, 34 years) completed the 2-year follow-up assessment tests. Three patients were excluded from the study after 1 year because two of them underwent retreatment and one was lost to follow-up.

Results At 2 years, no adverse events related to TIF were reported. A $\geq 50 \%$ improvement in GERD-HRQL scores compared with those at baseline on PPIs was sustained by $64 \%$ of patients. TIF was effective in eliminating heartburn in $93 \%$ of patients and daily PPI therapy in $71 \%$ of patients. Significantly $(p<0.05)$ more patients were able to consume reflux-causing foods and maintain lifestyle activities without GERD symptoms compared with baseline on PPIs. Fundoplications were durable and maintained their geometric dimensions. TIF was effective in eliminating hiatal
\end{abstract}

G.-B. Cadière ( $\square)$

Department of Gastrointestinal Surgery, Centre Hospitalier Universitaire St. Pierre, 322, rue Haute, Brussels 1000, Belgium e-mail: Guy-Bernard_CADIERE@stpierre-bru.be

N. Van Sante · A. Rajan

Department of Endoscopy, Clinique du Parc Léopold,

CHIREC, Brussels, Belgium

J. E. Graves · A. K. Gawlicka

EndoGastric Solutions, Inc., Redmond, WA, USA hernia in $60 \%$ of patients and esophagitis in $55 \%$ of patients. Global assessment of all outcomes in each patient revealed that $79 \%$ of patients experienced complete cure $(29 \%)$ or remission $(50 \%)$ of GERD at 2 years after TIF.

Conclusion The results at 2 years supported the longterm safety and durability of TIF and its sustained effect on the elimination of heartburn, esophagitis, $\leq 2 \mathrm{~cm}$ hiatal hernia, and daily dependence on PPIs.

Keywords Antireflux barrier - Diet . Gastroesophageal reflux disease $\cdot$ Heartburn . Hiatal hernia $\cdot$ Lifestyle

An effective treatment for gastroesophageal reflux disease (GERD) is expected to relieve symptoms, heal esophagitis (if present), and prevent chronic complications [1-3]. Depending on the stage of the disease, patients are treated with antisecretory medication (usually a proton pump inhibitor, PPI) or referred for antireflux surgery (usually performed laparoscopically) [2]. Short-term gastric acid suppression with antisecretory medication results in a rapid remission of symptoms and healing of esophagitis within 4-8 weeks [4-7]. However, 30-40\% of patients with GERD do not respond symptomatically to a standard dose of PPIs, and $50-75 \%$ of patients experience relapse of symptoms and esophagitis after cessation of treatment $[5,6,8,9]$. Patients who are unresponsive to PPIs, show intolerance to PPIs, have a large hiatal hernia, or prefer not to take medication long-term are referred for antireflux surgery [10]. Although antireflux surgery has been shown to be more effective than PPIs in long-term management of chronic GERD, patients are reluctant to undergo surgery because of associated risks and side effects [11-15]. An 
effective endoscopic (transoral) procedure that can cure reflux without considerable risks and side effects could be a valid alternative treatment for the $30 \%$ of patients with GERD who do not respond symptomatically to PPIs and, eventually, undergo laparoscopic procedure within 3-5 years of therapy, and those who are managed successfully with PPIs but are unwilling to take daily medication for the rest of their lives. For those patients with unmet needs, an earlier endoscopic intervention might represent the best therapeutic option [1, 16-18].

A novel antireflux transoral incisionless fundoplication (TIF) using EsophyX (EndoGastric Solutions, Redmond, WA, USA) was designed to construct an anterior partial fundoplication of 270 degrees by attaching the fundus to the anterior and left lateral wall of the distal esophagus slightly below the esophagogastric junction. Two clinical trials demonstrated the safety and effectiveness of TIF in treating patients with chronic GERD at 1 year [19, 20]. This study reports the 2-year follow-up results from the feasibility study that evaluated the safety and durability of TIF.

\section{Patients and methods}

This single-center feasibility study was conducted according to a clinical investigational protocol approved by the ethics committee at the Centre Hospitalier Universitaire St. Pierre, Brussels, Belgium [19]. Patients $(n=19)$ were enrolled if they had chronic symptomatic GERD lasting more than 6 months, a small hiatal hernia, were treated with daily PPI therapy, showed anatomic deterioration of esophagogastric junction, and signed informed consent. Patients were excluded if they had a body mass index (BMI) $\geq 30 \mathrm{~kg} \mathrm{~m}^{-2}$, esophagitis grade $\mathrm{D}$ in the Los Angeles classification [21], irreducible hiatal hernia $>3 \mathrm{~cm}$, esophageal or gastric emptying diseases, or previously failed antireflux procedures.

Initial screening assessment was conducted without discontinuation of PPIs and consisted of the nine-question GERD health-related quality-of-life (GERD-HRQL) [22], 24-hour ambulatory pH-metry [23, 24], upper GI endoscopy, esophageal biopsy, esophageal manometry, medical history, and GERD medication usage as described previously $[19,20]$. In addition, we assessed each patient's ability to consume foods and beverages commonly associated with triggering GERD symptoms, such as citrus, strawberries, tomatoes, chocolate, fatty foods, deep-fried foods, spicy foods, carbonated drinks, tea, coffee, caffeinated drinks, and alcohol [25]. Patients were asked whether they were able ("yes") or unable ("no") to consume each of the following foods and beverages without symptoms of GERD. The effect of GERD on lifestyle activities was assessed by asking patients whether they could eat late at night, smoke, drink alcohol, or exercise 1 hour after a meal without GERD symptoms. Dietary and lifestyle changes were recorded using case report forms (CRFs).

The TIF procedure was performed under general anesthesia with nasal or transoral intubation and following the standard TIF 1 protocol [19, 20, 26]. The device was inserted transorally into the esophagus with the patient in the left-lateral position. Hiatal hernia, if present, was reduced by returning the squamocolumnar junction to its natural position below the diaphragm using a built-in vacuum invaginator. During a single insertion, a partial anterior fundoplication was constructed through retraction of full-thickness plications and tailored placement of multiple fasteners circumferentially around the gastroesophageal junction starting on the greater curve side of the valve [19].

The follow-up assessment tests at 2 years consisted of GERD-HRQL questionnaire, upper GI endoscopy, GERD medication usage, and questions related to diet and lifestyle activity changes. The long-term durability of TIFs was evaluated by comparing their geometric aspects, including valve length, defined as the length (in centimeters) from the apex of the fundus to the valve lip [27], circumference, defined as the distance in degrees between the two most distant points of esophagogastric valve, as well as Hill grade [28] and adherence to the endoscope through the duration of the study using published and unpublished data from the same study [19]. A global assessment of all outcome measures was performed for each patient to determine the long-term effectiveness of TIF in curing GERD [20]. Patients were considered "cured" if they had no more heartburn or regurgitation, eliminated esophagitis and hiatal hernia, and discontinued all usage of PPIs. Patients were considered "improved" if they had reduced heartburn, esophagitis, or hiatal hernia and required occasional PPI therapy.

\section{Statistical analysis}

Primary endpoint success was $\geq 50 \%$ improvement (reduction) in GERD-HRQL scores at 2 years compared with those at baseline on PPIs. The total GERD-HRQL scores were calculated by summing the responses to nine questions [22]. The heartburn score was calculated by summing the responses to the first six questions. Absent or rare heartburn (scores $\leq 2$ to each of the six questions, or total score $\leq 12$ ) was indicative of heartburn elimination. Patients' satisfaction with their health condition was evaluated based on question 10: "very satisfied," "satisfied," "neutral," or "dissatisfied." Because of nonsymmetrical data distributions, $p$ values for changes from baseline to 2 years for GERD-HRQL scores were calculated by using 
the Mann-Whitney test (College Station, PA, USA). Secondary endpoint success was a total cessation of PPIs, hiatal hernia elimination, and esophagitis healing. Patients taking PPIs between the 1- and 2-year visits were excluded from calculations of esophagitis healing rate to avoid type 1 error, because the usage of medication represented a confounding variable to the effect of TIF on esophagitis improvement. The frequency of "yes" and "no" responses to questions related to symptoms, dietary and lifestyle activity changes was tested for significance using Spearman's rank correlation followed by the Mann-Whitney test. Patients who did not smoke, exercise, or drink alcohol were excluded from the analysis of these activities. Durability of TIF restoration was assessed by comparing TIF length and circumference during the duration of the study using the Mann-Whitney test. Values with $p<0.05$ were considered significant for all tests.

\section{Results}

\section{Patient characteristics}

Fourteen of 17 patients completed the 2-year follow-up assessment. Two of the remaining patients underwent retreatment and one was lost to follow-up. They were excluded from the analysis at 2 years because of the lack of data. Patient 001 and 003 underwent retreatment after 1 year with laparoscopic Nissen and TIF2 procedure, respectively, because they continued to experience symptoms and required daily PPIs [19]. The retreated patients were considered failures per intent-to-treat analysis and omitted from analysis of efficacy data per protocol. The third patient (008) was lost to follow-up at 2 years because of the lack of contact.

Patients ( $n=14,50 \%$ female) available at 2 years had a median age of 34 (range, 23-55) years and a median BMI of $22(18-31) \mathrm{kg} / \mathrm{m}^{2}$. Patients had suffered from GERD for a median of 10 (range, 3-15) years and were on continuous daily PPI therapy for a median of 6 (range, 2-13) years before undergoing TIF. Median GERD-HRQL score was 17 (range, 12-31) at baseline on PPIs. Upper GI endoscopy at baseline showed evidence of loose adherence of the esophagogastric junction and reflux esophagitis in all patients. A sliding hiatal hernia with $2 \mathrm{~cm}(n=7)$ or $3 \mathrm{~cm}$ $(n=3)$ in length was demonstrated endoscopically in ten (71\%) patients.

The median follow-up period was 25 (range, 24-27) months. No adverse events related to the TIF procedure occurred between the 1- and 2-year follow-up visits. Based on the answers to questions 7-9 of the GERD-HRQL questionnaire, daily difficulty in swallowing without pain was reported by one patient, and daily bloating or gassy feelings were reported by seven patients. The prevalence of these symptoms did not differ significantly compared with baseline on PPIs: $1(7 \%)$ and $8(57 \% ; p=0.6)$ in both cases.

At 2 years, GERD-HRQL scores improved significantly ( $p=0.004$ ) by a median of $59 \%$ compared with baseline on PPIs (7 vs. 17), and a clinically significant improvement of scores was demonstrated in nine (64\%) patients (Table 1). Heartburn scores ranged from 0 to 13 at 2 years compared with 12 and 31 at baseline on PPIs. Scores $\leq 12$ indicative of heartburn elimination were reported by $13(93 \%)$ patients. A total of $86 \%$ of patients were satisfied with the outcomes of the TIF procedure and only one patient was dissatisfied. Discontinuation of daily PPI therapy was sustained in ten $(71 \%)$ patients.

Analysis of dietary changes indicated that significantly more patients were able to consume citrus $(p=0.049)$, deep-fried foods $(p=0.018)$, spicy foods $(p=0.001)$, carbonated drinks $(p=0.006)$, coffee $(p=0.001)$, caffeinated drinks ( $p=0.043)$, and alcohol $(p=0.002)$ without GERD symptoms at 2 years compared with baseline on PPIs (Fig. 1). Analysis of lifestyle changes indicated that significantly more patients were able to eat late at night $(p=0.022)$, exercise $(p<0.001)$, smoke $(p=0.027)$, and drink alcohol $(p=0.001)$ compared with screening on PPIs.

Upper GI endoscopy revealed that the EsophyX-created fundoplications had a median length of $3 \mathrm{~cm}$, circumference of 200 degrees, tight or moderate adherence, and Hill grade 1 or 2 (Figs. 2-3; Table 2). Hiatal hernia was eliminated in $60 \%$ of patients and reduced in an additional $20 \%$ of patients. A hiatal hernia of $2 \mathrm{~cm}$ was newly revealed in one patient. Esophagitis was eliminated in $55 \%$ of patients without taking daily PPIs but remained unchanged in five patients who had TIF with loose $(n=3)$ or moderate $(n=2)$ adherence (Fig. 4; Table 2). The median TIF length at 2 years was $27 \%$ lower than that measured at the time of procedure and $0.5 \mathrm{~cm}$ less than that measured at 3 months. There was no significant difference between the median length at 2 years and that at 3 months $(p=0.2)$, 6 months $(p=0.2)$, and 12 months ( $p=0.6$; Fig. 5). The median TIF circumference at 2 years was $14 \%$ lower than that measured at the time of procedure and 10 degrees less than that measured at 3 months. There was no significant difference between the median circumference at 2 years and that at 3 months $(p=0.6), 6$ months $(p=0.3)$, and 12 months ( $p=0.2$; Fig. 6).

Global assessment revealed that $79 \%$ of patients experienced complete cure $(29 \%)$ or remission $(50 \%)$ of GERD at 2 years after TIF. The cured patients had no more heartburn, esophagitis, and hiatal hernia (Table 2) and those in remission experienced an elimination of heartburn and reduction of their hiatal hernia or esophagitis. The 
Table 1 GERD-HRQL scores and PPI usage at 2 years after transoral incisionless fundoplication (TIF)

\begin{tabular}{|c|c|c|c|c|c|c|c|}
\hline \multirow[t]{2}{*}{ Patient } & \multicolumn{3}{|c|}{ GERD-HRQL scores } & \multicolumn{2}{|c|}{ Heartburn scores } & \multirow[t]{2}{*}{ Satisfaction index } & \multirow[t]{2}{*}{ PPI usage } \\
\hline & $\begin{array}{l}\text { Before TIF } \\
\text { on PPIs }\end{array}$ & $\begin{array}{l}2 \text { Years } \\
\text { after TIF }\end{array}$ & $\begin{array}{l}\text { Change } \\
(\%)^{\mathrm{a}}\end{array}$ & $\begin{array}{l}\text { Before TIF } \\
\text { on PPIs }\end{array}$ & $\begin{array}{l}2 \text { Years } \\
\text { after TIF }\end{array}$ & & \\
\hline 002 & 15 & 16 & -7 & 15 & 13 & Satisfied & Daily \\
\hline 004 & 16 & 1 & 94 & 12 & 0 & Very satisfied & None \\
\hline 005 & 14 & 13 & 7 & 13 & 12 & Very satisfied & None \\
\hline 006 & 16 & 1 & 94 & 16 & 1 & Very satisfied & None \\
\hline 007 & 21 & 9 & 57 & 19 & 8 & Satisfied & None \\
\hline 009 & 12 & 7 & 42 & 12 & 7 & Satisfied & None \\
\hline 010 & 23 & 20 & 13 & 20 & 11 & Unsatisfied & Daily \\
\hline 012 & 16 & 6 & 63 & 13 & 5 & Satisfied & None \\
\hline 013 & 27 & 2 & 93 & 22 & 2 & Very satisfied & None \\
\hline 014 & 17 & 4 & 76 & 13 & 4 & Very satisfied & None \\
\hline 015 & 25 & 6 & 76 & 19 & 5 & Satisfied & None \\
\hline 016 & 21 & 9 & 57 & 15 & 9 & Satisfied & Occasional \\
\hline 017 & 31 & 16 & 48 & 26 & 12 & Neutral & Daily \\
\hline 018 & 15 & 6 & 60 & 15 & 6 & Satisfied & None \\
\hline \multicolumn{8}{|l|}{$n=14$} \\
\hline Median (range) & $17(12-31)$ & $7(1-20)$ & $\begin{array}{l}59(-7 \text { to } 94) \\
p=0.004\end{array}$ & $15(12-26)$ & $7(0-13)$ & & \\
\hline \multirow[t]{3}{*}{ n $(\%)$} & & & Improved $^{\mathrm{b}}$ & Eliminated $^{\mathrm{c}}$ & Eliminated $^{\mathrm{c}}$ & Satisfied $12(86 \%)$ & None \\
\hline & & & $9(64 \%)$ & $2(14 \%)$ & $13(93 \%)$ & Unsatisfied $1(7 \%)$ & $10(71 \%)$ \\
\hline & & & & & & Neutral 1 (7\%) & \\
\hline
\end{tabular}

${ }^{a}$ Positive values indicate improvement (reduction) in the scores

${ }^{\mathrm{b}}$ Defined by clinically significant reduction of scores $\geq 50 \%$ compared with baseline taking PPIs

${ }^{c}$ Defined by heartburn scores $\leq 12$ with $\leq 2$ (rare) scores per each of six questions

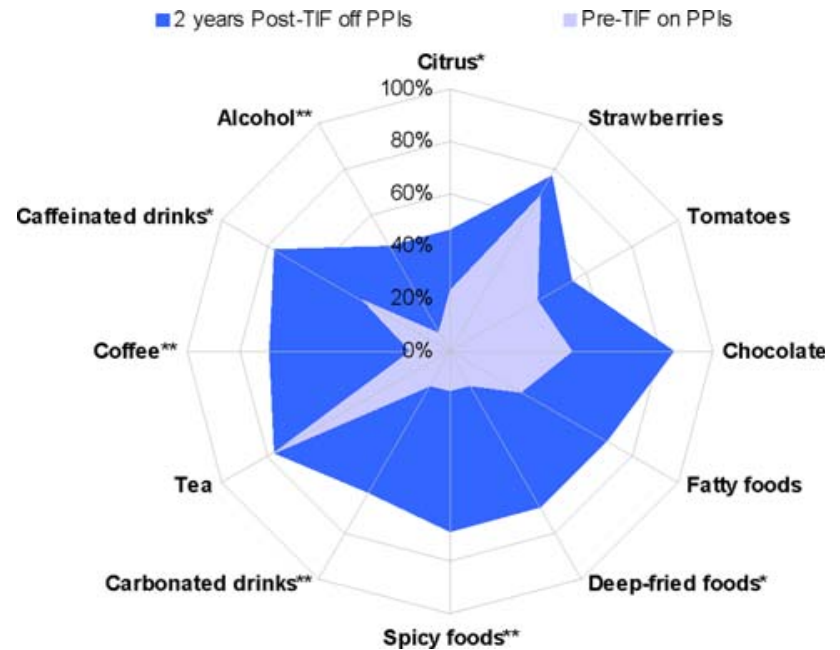

Fig. 1 Percentage of patients who were able to consume foods and beverages without GERD symptoms 2 years after transoral incisionless fundoplication (TIF) while not taking PPIs (blue field) compared with before TIF while taking PPIs (purple field). Significant differences indicated by $*$ if $p<0.05$, or $* *$ if $p<0.01$

remaining $21 \%$ of patients, with ongoing GERD, continued to experience heartburn and required daily PPI therapy. Comparison of the scores did not reveal any significant differences between the successful patients who were cured or in remission of GERD and those with ongoing GERD. Among cured patients (004, 006, 012, and 014), most had normal $\mathrm{pH}$ scores before the procedure while taking PPIs (004, 006, and 012) and also at 1 year while not taking PPIs (004, 006, and 014). Among seven patients who were in remission, normal $\mathrm{pH}$ scores were reported in 012 and 018 before the procedure while taking PPIs, in 007 and 015 at 1 year while not taking PPIs, and in 005 and 016 during both periods. Similarly, among three unsuccessful patients (002, 010, and 017) who had ongoing GERD and required daily PPIs, two had normal $\mathrm{pH}$ scores before the procedure while taking PPIs and at 2 years (002 and 010). The two retreated patients (001 and 003) also had normal $\mathrm{pH}$ scores before TIF while taking PPIs and pathologic $\mathrm{pH}$ at 1 year.

\section{Discussion}

The study population consisted of patients with advanced stages of chronic GERD who are typically referred for surgery [10, 29, 30]. The patients had suffered from the disease for more than 10 years and had continuous daily 
Fig. 2 Endoscopic retroflexed images of the esophagogastric junctions in patient 009 (top) and 016 (bottom) before (left) and 2 years after (right) transoral incisionless fundoplication
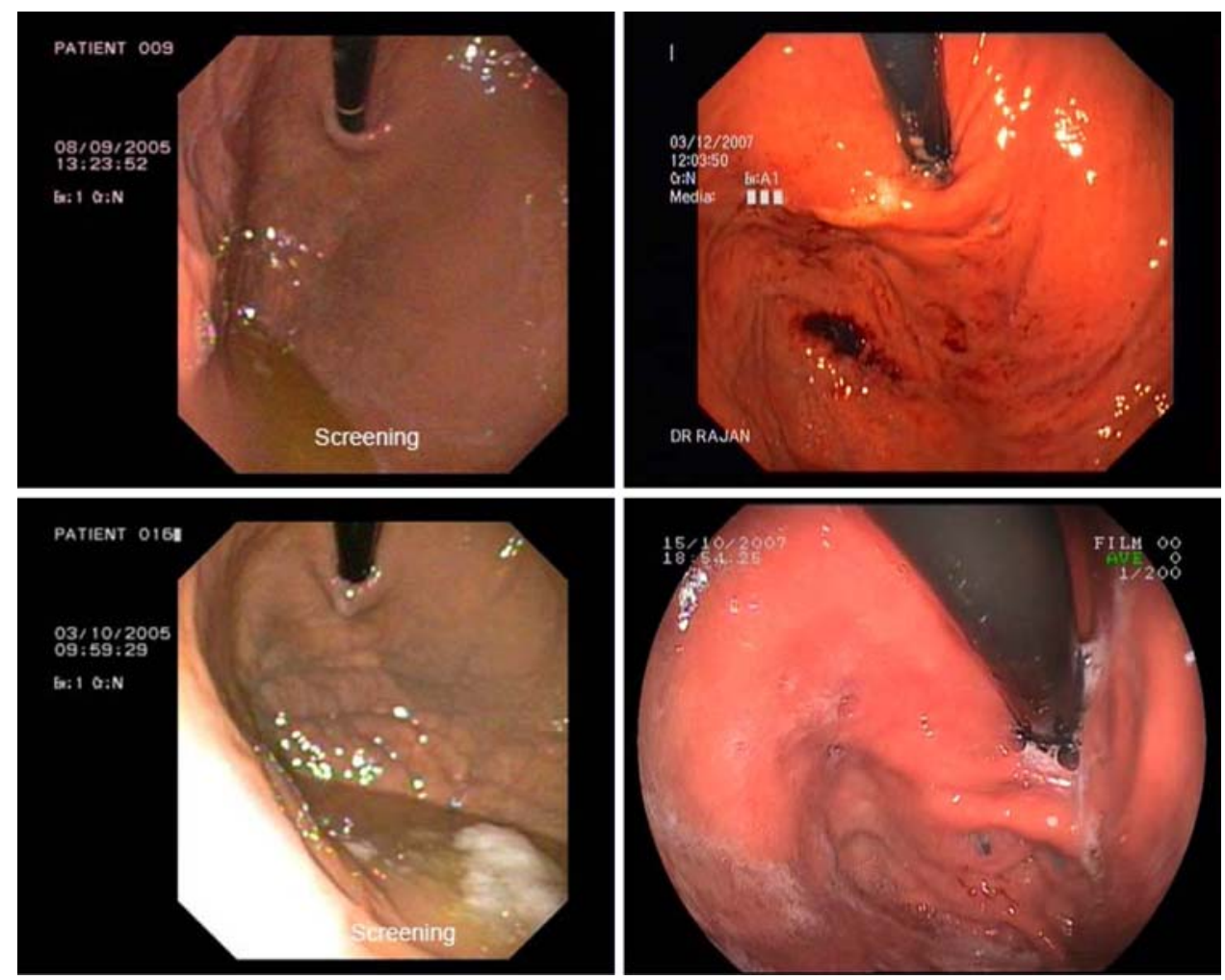

PPI therapy for more than 6 years before undergoing the TIF procedure. Despite having daily PPI therapy, patients continued to suffer from daily heartburn and esophagitis. Such a high prevalence of esophagitis was indicative of prolonged dysfunctionality of the antireflux barrier resulting, most likely, from anatomic deterioration of the esophagogastric junctions in those patients. Upper GI endoscopy revealed that the esophagogastric junctions in all patients had loose adherence and $59 \%$ of patients had a 2- to 3-cm hiatal hernia. Complete control of reflux in this population of patients could only be achieved through antireflux surgery, which has been shown more effective than PPIs in terms of patient satisfaction and clinical outcome because of its ability to reconstruct the biomechanics and physiology of the esophagogastric junction [11-14, 27, 31]. It is foreseeable that this population of patients with chronic GERD requiring long-term medical therapy would benefit from early surgery, which has been demonstrated in several randomized, controlled trials [15, 30, 32].

The absence of TIF-related adverse events supported long-term safety of TIF. Although gas bloating and gassy feelings were experienced daily by $50 \%$ of patients, they were not more frequent than while patients were undergoing PPI therapy. The gas bloating after antireflux surgery often is associated with dysphagia and the inability of patients to belch or vent after "well-constructed" fundoplication [10]. In general, partial (180-270-degree) fundoplication is associated with less dysphagia and gas- related side effects than a full fundoplication [33, 34]. The "tailored," "transoral," and "incisionless" nature of the TIF procedure using EsophyX is at the basis of its low invasiveness, which has been supported by few, mild, and transient postoperative side effects and the absence of longterm side effects as reported in the current article [19, 20].

The TIF procedure appeared to be more effective than PPIs in controlling symptoms in $64 \%$ of patients whose GERD-HRQL scores at 2 years were at least $50 \%$ better than those at baseline on PPIs. Moreover, TIF achieved an effective control of heartburn in $93 \%$ of patients and resulted in complete elimination of the need for antisecretory medication in $71 \%$ of patients. Heartburn is the most prevalent and troublesome symptom of GERD, and its elimination has been associated with improved wellbeing of patients [35-37]. The effective elimination of heartburn and increased dietary choices and lifestyle activities sustained higher patient's satisfaction with the TIF procedure. These initial long-term results suggested that patients experienced a sustained higher quality of life after TIF than they had on PPI therapy.

The maintenance of the geometric aspects and tight-tomoderate adherence of the fundoplications in the majority of patients during 2 years was supportive of the long-term durability of TIF. The $27 \%$ and $14 \%$ decrease during 2 years in the median length and circumference, respectively, could have been overestimated by the presence of edema at the time of intraoperative measurements. 
Table 2 Upper GI endoscopy and global assessment at 2 years after transoral incisionless fundoplication

\begin{tabular}{|c|c|c|c|c|c|c|c|c|c|c|c|c|}
\hline \multirow[t]{2}{*}{ Patient } & \multirow{2}{*}{$\begin{array}{l}\text { Length } \\
(\mathrm{cm})\end{array}$} & \multirow{2}{*}{$\begin{array}{l}\text { Circumference } \\
\text { (degree) }\end{array}$} & \multirow{2}{*}{$\begin{array}{l}\text { Adherence/ } \\
\text { Hill grade }\end{array}$} & \multicolumn{3}{|c|}{ Hiatal hernia $(\mathrm{cm})$} & \multicolumn{3}{|c|}{ Esophagitis (grade) } & \multirow[t]{2}{*}{ Cured $^{c}$} & \multirow{2}{*}{$\begin{array}{l}\text { In } \\
\text { remission }\end{array}$} & \multirow[t]{2}{*}{ Ongoing $^{\mathrm{e}}$} \\
\hline & & & & Before $^{a}$ & $1 \mathrm{yr}^{\mathrm{a}}$ & $2 \mathrm{yr}$ & Before $^{\mathrm{a}}$ & $1 \mathrm{yr}^{\mathrm{a}}$ & $2 \mathrm{yr}$ & & & \\
\hline 002 & 3 & 210 & Moderate/2 & 2 & 0 & 0 & A & $\mathrm{A}$ & None $^{\mathrm{b}}$ & - & - & Yes \\
\hline 004 & 4 & 210 & Moderate/2 & 0 & 0 & 0 & $\mathrm{C}$ & $\mathrm{A}$ & None & Yes & - & - \\
\hline 005 & 3 & 230 & Moderate/3 & 3 & 0 & 0 & $\mathrm{C}$ & A & $\mathrm{C}$ & - & Yes & - \\
\hline 006 & 4 & 200 & Tight/1 & 0 & 0 & 0 & A & None & None & Yes & - & - \\
\hline 007 & 3 & 180 & Loose/3 & 2 & 2 & 0 & A & $\mathrm{A}$ & A & - & Yes & - \\
\hline 009 & 3 & 200 & Moderate/2 & 2 & 0 & 2 & $\mathrm{~A}$ & $\mathrm{~B}$ & None & - & Yes & - \\
\hline 010 & 3 & 180 & Moderate/2 & 2 & 2 & 0 & $\mathrm{~A}$ & A & None $^{\mathrm{b}}$ & - & - & Yes \\
\hline 012 & 3 & 180 & Moderate/2 & 2 & 0 & 0 & A & None & None & Yes & - & - \\
\hline 013 & 3 & 210 & Moderate/2 & 2 & 2 & 2 & A & A & A & - & Yes & - \\
\hline 014 & 4 & 200 & Tight/1 & 0 & 0 & 0 & A & A & None & Yes & - & - \\
\hline 015 & 3 & 90 & Loose/3 & 3 & 2 & 1 & A & B & A & - & Yes & - \\
\hline 016 & 4 & 210 & Moderate/1 & 0 & 0 & 2 & A & None & None & - & Yes & - \\
\hline 017 & 3 & 180 & Loose/3 & 3 & 2 & 0 & B & $\mathrm{B}^{\mathrm{b}}$ & $\mathrm{A}^{\mathrm{b}}$ & - & - & Yes \\
\hline 018 & 2 & 200 & Loose/3 & 2 & 0 & 1 & A & A & A & - & Yes & - \\
\hline \multicolumn{13}{|l|}{$n=14$} \\
\hline $\begin{array}{l}\text { Median } \\
\quad \text { (range) }\end{array}$ & $3(2-4)$ & $200(90-230)$ & & & & & & & & & & \\
\hline$n(\%)$ & $\geq 3 \mathrm{~cm}$ & $\geq 180$ degree & $\geq$ Moderate & Eliminat & & & Eliminat & $\mathrm{ted}^{\mathrm{b}}$ & & 4 & $(29 \%)$ & $7(50 \%)$ \\
\hline \multicolumn{13}{|l|}{$3(21 \%)$} \\
\hline & $13(93 \%)$ & $13(93 \%)$ & $10(71 \%)$ & \multicolumn{3}{|c|}{$6 / 10(60 \%)$} & \multicolumn{3}{|c|}{$6 / 11(55 \%)$} & & & \\
\hline & & & & $2 \mathrm{~cm}$ & $\begin{array}{l}4 / 7 \\
\quad(57 \%)\end{array}$ & & A & $\begin{array}{l}5 / 9 \\
\quad(56 \%)\end{array}$ & & & & \\
\hline & & & & $3 \mathrm{~cm}$ & $\begin{array}{l}2 / 3 \\
\quad(67 \%)\end{array}$ & & B & $0 / 1(0 \%)$ & & & & \\
\hline & & & & & & & $\mathrm{C}$ & $\begin{array}{l}1 / 2 \\
\quad(50 \%)\end{array}$ & & & & \\
\hline
\end{tabular}

a Values from Cadière et al (2008) [19]

${ }^{\mathrm{b}}$ Patients on daily PPIs were excluded from calculations

${ }^{c}$ Cured patients had no more heartburn, PPI daily dependence, hiatal hernia and esophagitis at 2 years [20]

${ }^{\mathrm{d}}$ In remission patients had reduced heartburn, hiatal hernia or esophagitis but required occasional usage of PPIs [20]

e Patients with ongoing GERD had heartburn, hiatal hernia or esophagitis, and required daily PPIs [20]

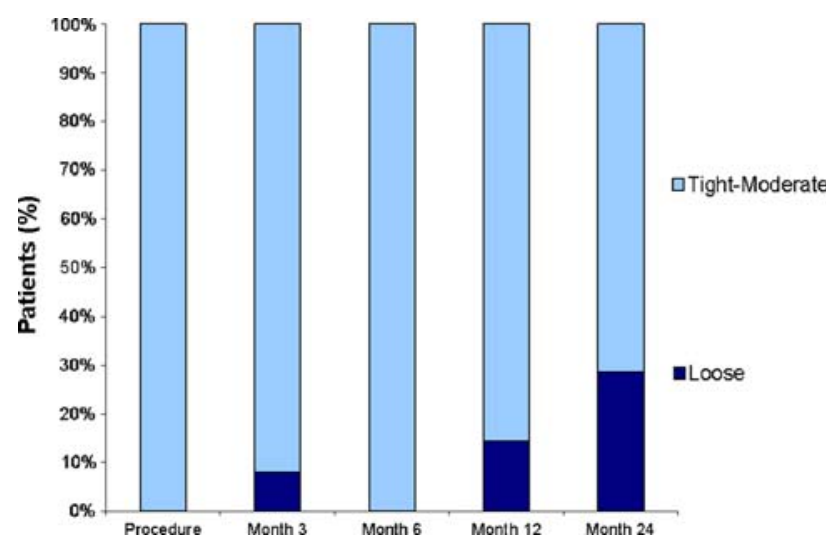

Fig. 3 Adherence of transoral incisionless fundoplications through 2year duration of the study

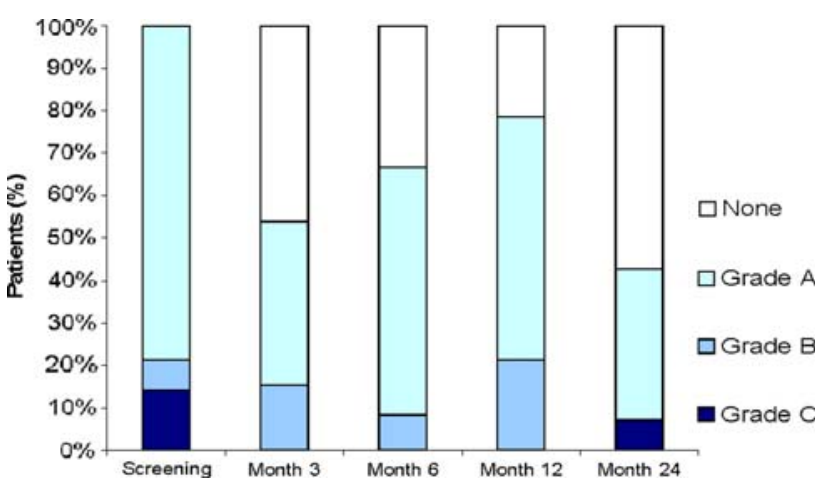

Fig. 4 Prevalence of esophagitis before and during a 2-year period after the transoral incisionless fundoplication procedure. Grades according to the Los Angeles classification [21] 


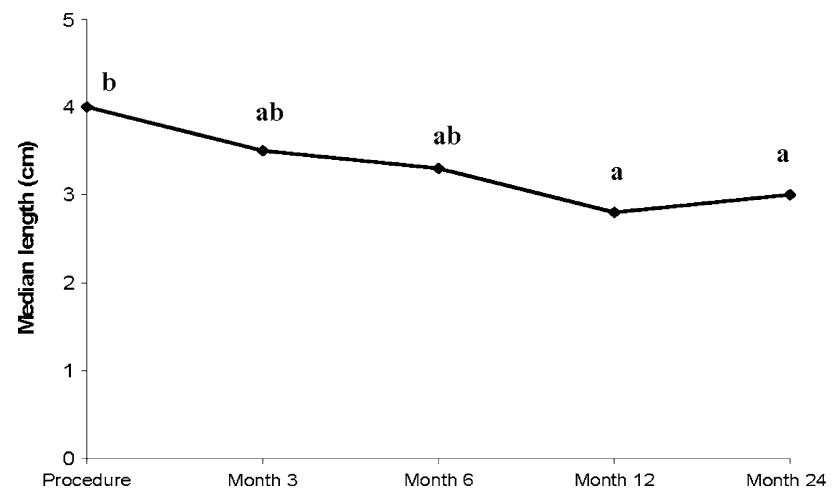

Fig. 5 Median length of transoral incisionless fundoplications through 2 years of the study. Values with different letters were significantly different $(p<0.05)$

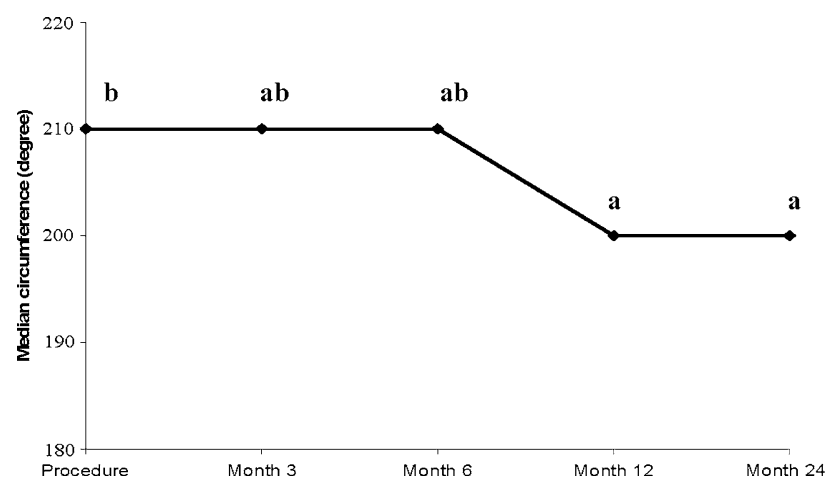

Fig. 6 Median circumference of transoral incisionless fundoplications through 2 years of the study. Values with different letters were significantly different $(p<0.05)$

Therefore, if we take the measurements without edema at 3 months, the decrease of $0.5 \mathrm{~cm}$ and 10 degrees during the ensuing 2 years was small and not significant. Moreover, the elimination of small hiatal hernia in $60 \%$ of patients was durable and effective in sustaining the antireflux functions of TIF and promoted a 55\% higher healing rate of esophagitis than on PPIs. EsophyX continues to be the only transoral device that is capable of reducing small hiatal hernia [17]. Because the healing of esophagitis requires reduced acid exposure, the progression of healing in those patients who had normal $\mathrm{pH}$ at 1 year could be an objective indication of a sustained and effective reflux control by TIF.

Although the presented 2-year results were encouraging, they had a limited value for generalization because of the small study population and the exclusion of patients who required retreatment. A multicenter study is currently underway to evaluate the long-term efficacy of TIF in eliminating symptoms and normalizing acid exposure.

Disclosure The results were presented in part at the OESO 9th World Congress and DDW2008. This study was sponsored by EndoGastric Solutions, Inc., Redmond, WA, USA.
Open Access This article is distributed under the terms of the Creative Commons Attribution Noncommercial License which permits any noncommercial use, distribution, and reproduction in any medium, provided the original author(s) and source are credited.

\section{References}

1. Spicak J (2007) Treatment of gastroesophageal reflux disease: endoscopic aspects. Dig Dis 25:183-187

2. Tytgat GN, McColl K, Tack J, Holtmann G, Hunt RH, Malfertheiner P, Hungin AP, Batchelor HK (2008) New algorithm for the treatment of gastro-oesophageal reflux disease. Aliment Pharmacol Ther 27:249-256

3. Wolfe MM, Lowe RC (2007) Investing in the future of GERD. J Clin Gastroenterol 41(Suppl 2):S209-S216

4. Bardhan KD, Achim A, Riddermann T, Pfaffenberger B (2007) A clinical trial comparing pantoprazole and esomeprazole to explore the concept of achieving "complete remission" in gastro-oesophageal reflux disease. Aliment Pharmacol Ther 25:1461-1469

5. Fass R, Shapiro M, Dekel R, Sewell J (2005) Systematic review: proton-pump inhibitor failure in gastro-oesophageal reflux disease: where next? Aliment Pharmacol Ther 22:79-94

6. Fass R (2007) Proton-pump inhibitor therapy in patients with gastro-oesophageal reflux disease: putative mechanisms of failure. Drugs 67:1521-1530

7. Hunt RH, Yuan Y, Yaghoobi M (2007) GERD: new strategies and new failures. J Clin Gastroenterol 41(Suppl 2):S72-S80

8. Carlson R, Dent J, Watts R, Riley S, Sheikh R, Hatlebakk J, Haug K, de Groot G, van Oudvorst A, Dalvag A, Junghard O, Wiklund I, Group TIGS (1999) Gastro-oesophageal reflux disease in primary care: an international study of different treatment strategies with omeprazole. Euro J Gastroenterol Hepatol 10:119-124

9. Inadomi JM, McIntyre L, Bernard L, Fendrick AM (2003) Stepdown from multiple- to single-dose proton pump inhibitors (PPIs): a prospective study of patients with heartburn or acid regurgitation completely relieved with PPIs. Am J Gastroenterol 98:1940-1944

10. Lundell L (2004) Surgery of gastroesophageal reflux disease: a competitive or complementary procedure? Dig Dis 22:161-170

11. Allgood PC, Bachmann M (2000) Medical or surgical treatment for chronic gastroesophageal reflux? A systematic review of published evidence of effectiveness. Eur J Surg 166:713-721

12. Cookson R, Flood C, Koo B, Mahon D, Rhodes M (2005) Shortterm cost effectiveness and long-term cost analysis comparing laparoscopic Nissen fundoplication with proton-pump inhibitor maintenance for gastro-oesophageal reflux disease. Br J Surg 92:700-706

13. Lundell L, Miettinen P, Myrvold HE, Hatlebakk JG, Wallin L, Malm A, Sutherland I, Walan A (2007) Seven-year follow-up of a randomized clinical trial comparing proton-pump inhibition with surgical therapy for reflux oesophagitis. Br J Surg 94:198-203

14. Mahon D, Rhodes M, Decadt B, Hindmarsh A, Lowndes R, Beckingham I, Koo B, Newcombe RG (2005) Randomized clinical trial of laparoscopic Nissen fundoplication compared with proton-pump inhibitors for treatment of chronic gastrooesophageal reflux. Br J Surg 92:695-699

15. Anvari M, Allen C, Marshall J, Armstrong D, Goeree R, Ungar W, Goldsmith C (2006) A randomized controlled trial of laparoscopic Nissen fundoplication versus proton pump inhibitors for treatment of patients with chronic gastroesophageal reflux disease: one-year follow-up. Surg Innov 13:238-249

16. Fry LC, Monkemuller K, Malfertheiner P (2007) Systematic review: endoluminal therapy for gastro-oesophageal reflux 
disease: evidence from clinical trials. Eur J Gastroenterol Hepatol 19:1125-1139

17. Marchese M, Spada C, Costamagna G (2006) Endoluminal fundoplication. Minim Invasive Ther Allied Technol 15:356-365

18. Watson DI (2008) Endoscopic antireflux surgery: are we there yet? World J Surg 32:1578-1580

19. Cadiere GB, Rajan A, Germay O, Himpens J (2008) Endoluminal fundoplication by a transoral device for the treatment of GERD: a feasibility study. Surg Endosc 22:333-342

20. Cadiere GB, Buset M, Muls V, Rajan A, Rosch T, Eckardt AJ, Weerts J, Bastens B, Costamagna G, Marchese M, Louis H, Mana F, Sermon F, Gawlicka AK, Daniel MA, Deviere J (2008) Antireflux transoral incisionless fundoplication using EsophyX: 12month results of a prospective multicenter study. World J Surg 32:1676-1688

21. Lundell LR, Dent J, Bennett JR, Blum AL, Armstrong D, Galmiche JP, Johnson F, Hongo M, Richter JE, Spechler SJ, Tytgat GN, Wallin L (1999) Endoscopic assessment of oesophagitis: clinical and functional correlates and further validation of the Los Angeles classification. Gut 45:172-180

22. Velanovich V (2007) The development of the GERD-HRQL symptom severity instrument. Dis Esophagus 20:130-134

23. Pandolfino JE, Schreiner MA, Lee TJ, Zhang Q, Boniquit C, Kahrilas PJ (2005) Comparison of the Bravo wireless and Digitrapper catheter-based $\mathrm{pH}$ monitoring systems for measuring esophageal acid exposure. Am J Gastroenterol 100:14661476

24. Hirano I, Richter JE (2007) ACG practice guidelines: esophageal reflux testing. Am J Gastroenterol 102:668-685

25. Kaltenbach T, Crockett S, Gerson LB (2006) Are lifestyle measures effective in patients with gastroesophageal reflux disease? An evidence-based approach. Arch Intern Med 166:965-971

26. Cadiere GB, Rajan A, Rqibate M, Germay O, Dapri G, Himpens J, Gawlicka AK (2006) Endoluminal fundoplication (ELF) evolution of Esophy $\mathrm{X}^{\mathrm{TM}}$, a new surgical device for transoral surgery. Minim Invasive Ther Allied Technol 15:348-355

27. Jobe BA, Kahrilas PJ, Vernon AH, Sandone C, Gopal DV, Swanstrom LL, Aye RW, Hill LD (2004) Endoscopic appraisal of the gastroesophageal valve after antireflux surgery. Am J Gastroenterol 99:233-243

28. Hill LD, Kozarek RA, Kraemer SJ, Aye RW, Mercer CD, Low DE, Pope CE II (1996) The gastroesophageal flap valve: in vitro and in vivo observations. Gastrointest Endosc 44:541-547

29. Hinder RA, Filipi CJ, Wetscher G, Neary P, DeMeester TR, Perdikis G (1994) Laparoscopic Nissen fundoplication is an effective treatment for gastroesophageal reflux disease. Ann Surg 220:472-481

30. Lundell L, Miettinen P, Myrvold HE, Pedersen SA, Liedman B, Hatlebakk JG, Julkonen R, Levander K, Carlsson J, Lamm M, Wiklund I (2001) Continued (5-year) followup of a randomized clinical study comparing antireflux surgery and omeprazole in gastroesophageal reflux disease. J Am Coll Surg 192:172-181

31. Hunter JG, Trus TL, Branum GD, Waring JP, Wood WC (1996) A physiologic approach to laparoscopic fundoplication for gastroesophageal reflux disease. Ann Surg 223:673-685

32. Spechler SJ, Lee E, Ahnen D, Goyal RK, Hirano I, Ramirez F, Raufman JP, Sampliner R, Schnell T, Sontag S, Vlahcevic ZR, Young R, Williford W (2001) Long-term outcome of medical and surgical therapies for gastroesophageal reflux disease: follow-up of a randomized controlled trial. JAMA 285:2331-2338

33. Lundell L (2004) Complications after anti-reflux surgery. Best Pract Res Clin Gastroenterol 18:935-945

34. Watson DI, Jamieson GG, Pike GK, Davies N, Richardson M, Devitt PG (1999) Prospective randomized double-blind trial between laparoscopic Nissen fundoplication and anterior partial fundoplication. Br J Surg 86:123-130

35. Castell DO, Murray JA, Tutuian R, Orlando RC, Arnold R (2004) Review article: the pathophysiology of gastro-oesophageal reflux disease: oesophageal manifestations. Aliment Pharmacol Ther 20((Suppl) $)$ ): 14

36. Katz PO (2001) Gastroesophageal reflux disease: state of the art. Rev Gastroenterol Disord 1:128-138

37. Revicki DA, Crawley JA, Zodet MW, Levine DS, Joelsson BO (1999) Complete resolution of heartburn symptoms and healthrelated quality of life in patients with gastro-oesophageal reflux disease. Aliment Pharmacol Ther 13:1621-1630 